\title{
Assessing the Effectiveness of a Project-Based Laboratory Manual for a C Programming Course
}

\author{
Kristine K. Craven \\ Tennessee Technological University
}

\begin{abstract}
$\underline{\text { Abstract }}$
Programming for Engineers, Basic Engineering (BE) 1120, is a first-year course at Tennessee Technological University that is taught in a lecture/laboratory format. Traditionally the laboratory manual has been comprised of unrelated randomly selected exercises chosen mainly from the homework sections of the course textbook. A new project-based laboratory manual has been developed utilizing the solution to a complex engineering project, where each new section of the project solution is presented to coincide with the programming material being taught in the lecture portion of the class. In this work the change in laboratory manual format is assessed and the benefits and drawbacks are discussed.
\end{abstract}

For the 2001-2002 academic year, the students in BE 1120 were divided into two groups, of close to equal size, where one group used the traditional laboratory manual and the other group was given the new project-based laboratory manual. At the end of each semester, the students anonymously completed a survey to ascertain their opinion of the laboratory manual and its role in their learning of the material covered. The final grades received by the students were also examined, with the results indicating that the traditional laboratory manual group had an average grade point average (GPA) that was almost two-tenths of a point higher than the project-based laboratory manual group. Since the groups were chosen randomly, other possible factors such as academic preparedness could be shown to contribute to the higher GPA value seen. It is concluded that the type of laboratory manual used did not significantly affect the overall performance of the students.

\section{$\underline{\text { Introduction }}$}

There are as many approaches to teaching computer programming, as there are programming languages to teach. One method involves presenting the syntax and logic structures along with basic background information in a lecture environment and then implementing these concepts in a laboratory setting. The effect of the laboratory experience on the learning process is a function of the specific content of the laboratory exercises comprising the laboratory manual. One possible approach to the material presented in the laboratory manual utilizes unrelated simple programs found mainly in the homework exercises of the course textbook or developed by the instructor. Another possibility is to incorporate into the laboratory manual a more complex 
engineering project that is developed step-by-step within the laboratory exercises throughout the semester.

The basic concept behind the project-based laboratory manual is to give the students a practical application for the course material as well as a sense of accomplishment with the finished product. The finished product in BE 1120 will be a computer program that solves a complex engineering problem. Several institutions have incorporated project-based laboratory exercises, particularly into design type courses. However, no other example of implementation into a programming laboratory environment was found in the literature.

Faculty at Rose-Hulman Institute of Technology, who found that their Applied Optics majors needed to see practical application for their course material, developed a project-based laboratory where the students design and build a product. The authors report that the students felt that they learned the concepts better and there was a higher level of enthusiasm and pride among the students. ${ }^{1}$ The project presented in this work was first developed by several engineering faculty teaching different sections of same freshmen engineering lecture course offered at West Virginia University. ${ }^{2,3}$ The project was completed in several homework assignments that students worked on outside of the lecture meetings. This differs from the current implementation where the assignments are worked in the laboratory environment with instructor support. There were mixed results among the different sections that could be contributed to the variety of presentation styles used by different faculty members. The best results were seen in the section that contained Honor students who could more easily work with a complex problem and better understand the concepts required to finish the project. Among the remaining sections many of the students did not comprehend different components of the project and had difficulty in finishing the final program while others did not experience these limitations and thus experienced better results.

As a side benefit of the project-based approach, the students acquire some important engineering design techniques by learning to decompose a complex engineering project and then construct a solution. As each new programming structure or concept is introduced in the lecture, a new portion of the project is developed in the laboratory exercise that specifically uses those structures and concepts. Since this mimics what a practicing engineer would do while attempting to solve a complex problem, the students experience first hand how the process works. Thus it is believed that this approach would be more effective in facilitating the learning process and result in a better understanding of the course material. Torrey believed that a similar approach would benefit students in a power electronics course. ${ }^{4}$ His approach was to give the students opportunity to complete a project while reinforcing material covered in several courses they had previously taken. Torrey also gradually increases the responsibility of the students for the design of the circuitry. ${ }^{4}$ The project employed in the Basic Engineering (BE) 1120 laboratory manual gradually increases in complexity as the programming concepts become more difficult and the resulting computer program lengthens.

\section{Background}

The BE 1120 course at Tennessee Technological University is broken into two separate 
groups, one group is taught the FORTRAN programming language and the other group learns the $\mathrm{C}$ programming language. This paper will address the group in the $\mathrm{C}$ programming course, comprised of approximately 140 students who are further broken into five different sections of 28 students each. All 140 students attend a common lecture period that meets for two fifty-minute sessions per week. The 28 student sections then meet in a laboratory containing 14 computers for two fifty-minute sessions per week, at which time they worked in pairs to complete the laboratory assignments. Of these 140 students, only 112 (four of the laboratory sections) were used in the study in order to equate the number of students using each of the laboratory manual types. Two sections were given the traditional laboratory manual composed of random simple exercises from the textbook, and the other two sections were given the project-based laboratory manual. This situation was repeated in both the fall semester of 2001 and the spring semester of 2002 .

The laboratory manuals were organized into laboratory assignments that were completed during each laboratory session. There were 20 laboratory assignments that coincided with material presented in the lecture and which follow the chapters of the textbook. These laboratory assignments will be described in detail below. Laboratory assignments 21 and 22 were dedicated to an engineering project that was completed at the end of the semester. For the project-based manual, these last assignments were the final installments of the complex engineering project on which the laboratory manual was based. For the traditional laboratory manual, there was a new engineering project that was introduced and completed at this point in the semester. Both projects incorporated all of the concepts covered in the course.

Each laboratory assignment included laboratory preparation and laboratory exercises. Most assignments had two exercises. The laboratory preparation was to be completed prior to the laboratory meeting. As an incentive, extra credit on the next quiz was given for completion of the laboratory preparation. Examples of laboratory preparation included: development of an algorithm for one of the laboratory exercises, reading through the problem in the textbook that was to be assigned, or writing out program statements that were to be used in the laboratory exercises.

For both laboratory manual types, the first exercise of the laboratory assignment was generally the same and required the students to complete a program that was given to them with pieces missing. Once the program was completed, the students were required to test the program to assure that it was correct before proceeding to the second exercise. For the traditional laboratory manual, the second exercise was generally a program that must be completed by the students where the specific task of the program was taken from the homework section of the course textbook. On the other hand, the project-based laboratory manual required that the students write the next section in the project program for the second laboratory exercise. For both laboratory manual types, the exercises for the laboratory assignment focused on concepts being covered in the lecture period.

As stated above, the students work in pairs and have fifty minutes to finish each laboratory assignment. If they are unable to complete all of the assignment in the allotted time, the students are strongly encouraged to continue their work in the open lab hours. The laboratory rooms that are made available for open lab hours during the evening on weekdays and for specified hours on 
the weekend. The software being supported by the course is not generally available to the students, however they are given access to free $\mathrm{C}$ compilers and assistance is available for any student who chooses to purchase Microsoft Visual C, which is also available in the laboratory rooms.

\section{The Project-based Manual}

The complex engineering project that was chosen for this laboratory manual is based on intergalactic space travel. This project was originally developed at West Virginia University. ${ }^{2,3}$ The following project introduction is taken directly from the laboratory manual.

\section{Xetron Project}

Many of the exercises in the manual will follow a theme that when put together will complete an engineering related project. This project is outlined below.

You have met some new friends who invited you to their hometown to give you a party for your next birthday. As these are very interesting beings, you decided to accept and learned that they are from Xetron, a planet fifty five million miles away. Nervous, but excited, you packed your bags, boarded a Lockheed Martin X-33 spacecraft, and departed the Earth at 10:00 a.m. on Thursday January 10,2002 . You plan to arrive in time for the party that is scheduled to take place at 4:30 p.m. on your birthday.

You have since learned that Xetron is similar to Venus in size, density $(5,250$ $\left.\mathrm{kg} / \mathrm{m}^{3}\right)$, and mass $(4.88 \mathrm{e}+24 \mathrm{~kg})$ and has four moons that orbit it in circular paths.

\begin{tabular}{|c|c|c|c|}
\hline Moon & Mass $(\mathrm{kg})$ & Density $\left(\mathrm{kg} / \mathrm{m}^{3}\right)$ & Orbital Radius $(\mathrm{m})$ \\
\hline Xerox & $9.76 \mathrm{e}+23$ & 11,300 & $1.43 \mathrm{E}+07$ \\
\hline Xapetus & $4.067 \mathrm{e}+23$ & 10,500 & $1.92 \mathrm{E}+07$ \\
\hline Xalhalla & $2.44 \mathrm{e}+23$ & 8,920 & $2.33 \mathrm{E}+07$ \\
\hline Xassini & $9.76 \mathrm{e}+22$ & 7,860 & $2.67 \mathrm{e}+07$ \\
\hline
\end{tabular}

During your trip, the computer has told you that it seems that during the confusion of your departure from Earth one of the technicians forgot to upload some of the files into your navigation computer. There is no need to panic! Mission Probability Experts tell you that the fact you are still alive means that most of the files were uploaded correctly. That is great news! It would appear that the main module that is missing is the one that would guide the spaceship during its landing on Xetron. Therefore, it will be your job to rebuild the source code needed for the landing cycle of the craft. However, watch what you say, mission psychologists have warned not to use the word "Crash" in reference to the computer.

\section{LET THE JOURNEY BEGIN!!}


As has been stated, pieces of the Xetron project were then completed as to correspond with the textbook chapter material in 11 of the first 20 laboratory assignments. The first task was to compute the average velocity needed to reach Xetron at the desired time. This simple calculation was completed as the students were learning about variables, arithmetic, input, and output. When the lecture topic turned to conditional structures, the laboratory exercise required the students to make sure that it was possible to travel at this average velocity depending on the capabilities of the spacecraft. If the calculated average velocity was too high, then they must take an extra year for their trip. Similar additional modifications were required as the students learned repetition structures, user-defined functions, and array variables.

With the completion of Laboratory assignment 16 , the program was capable of computing the distance between the spacecraft and each of the moons in the Xetron system at any given instant during the trip. Laboratory assignment 21 describes (using a numbered list) how to modify this version of the program to determine if the spacecraft would crash into any of the moons as it approached Xetron when the user was allowed to prescribe the duration of the deceleration period for the spacecraft. The basic goal of the Xetron project was to determine an acceptable window of deceleration period lengths that would allow the spacecraft to land safely on Xeton. The procedure for accomplishing this was described in Laboratory assignment 22.

\section{The Traditional Manual}

Laboratory assignments 1 through 20 were randomly selected unrelated programs chosen mainly from the homework section of the corresponding chapter in the course textbook. Students in this group were, however, required to complete a smaller scale engineering project in Laboratory assignments 21 and 22. This project was based on John Conway's Game of Life, which simulates propagation of a colony of organisms. There is a set of rules that govern life and death for the colony that are applied over a number of generations while some basic statistics are kept. As with the Xetron project, this project incorporated all of the programming techniques and structures learned during the semester and its solution was given in the laboratory manual with similar detail.

\section{Observations and Results}

Unfortunately, even though it is felt that the Xetron project was divided into sufficiently simple steps, there did arise a considerable amount of confusion and frustration during the semester. The students had problems completing one step in particular and then became convinced that they would never be able to complete the project because they could not complete that one step. To alleviate this problem, the students were given a solution program, but the confusion and frustration were not eliminated. In the second semester of the project, the instructor spent more time explaining the basic concept behind the troublesome step, but the students continued to have problems with the programming. The belief that this particular task is not beyond the student's capability is supported by the fact that the same problem is given in the homework section of the textbook. However due to this main difficulty, the perception of the project-based laboratory manual was not favorable. 
With the traditional manual, the program tasks were very simple and many students did not see the reason for writing a program to perform such simple tasks, many of which could be easily completed with a calculator. These students were also more overwhelmed by the semester project that was completed in the last lab sessions of the semester; they saw it as an insurmountable task.

The students were given a survey that was completed anonymously at the end of each semester. The survey consisted of eleven statements with which the students could: strongly agree, agree, neither agree nor disagree, disagree, or strongly disagree. The results of the responses to the survey are summarized below.

Students using the traditional lab manual:

- felt more strongly that they put a sufficient amount of effort into completing the laboratory assignments than the project-based laboratory manual group felt that they did.

- believed that the laboratory exercises were the most helpful in learning the course material.

- indicated that there is a need to see the practical application of the programming techniques in order to fully understand them.

Students using the project-based lab manual:

- did not believe that a project-based manual reinforced the programming techniques taught in the class.

- disagreed that using the project-based manual helped them to understand how to approach and solve a large engineering project.

This data would indicate that the project-based laboratory manual did not achieve all of the desired outcomes. It was hoped that the students who completed the project-based laboratory manual would have an appreciation for the problem solving method employed by engineers.

Table 1: Comparison of Student Performance for Study Group.

\begin{tabular}{|c|c|c|c|c|c|c|}
\hline \multicolumn{3}{|c|}{ Project-based Manual } & Grade & \multicolumn{3}{c|}{ Traditional Manual } \\
\hline Fall & Spring & $\underline{\text { Total }}$ & & $\underline{\text { Fall }}$ & $\underline{\text { Spring }}$ & $\underline{\text { Total }}$ \\
\hline 6 & 11 & 17 & A & 12 & 11 & 23 \\
\hline 14 & 8 & 22 & B & 11 & 16 & 27 \\
\hline 8 & 9 & 17 & C & 11 & 9 & 20 \\
\hline 2 & 10 & 12 & D & 3 & 8 & 11 \\
\hline 2 & 5 & 7 & F & 4 & 2 & 6 \\
\hline 32 & 43 & 75 & Total & 41 & 46 & 87 \\
\hline \multicolumn{4}{|c|}{ Average GPA $=2.33$} & \multicolumn{3}{c|}{ Average GPA $=2.52$} \\
\hline
\end{tabular}

The table above summarizes the grades received by students who were in the course for the first time, attended class throughout the semester, and took the final exam. These numbers do indicate a slightly higher performance by the students using the traditional laboratory manual, with $6 \%$ more A's and B's than those using the project-based laboratory manual. A standard grade 
point average (GPA) calculation was applied to the grades received by the students in each category. The students using the project-based laboratory manual had an average GPA value that was less than two tenths of a grade point lower than those using the traditional laboratory manual.

Table 2: Average ACT Scores for Study Group.

\begin{tabular}{|c|c|c|}
\hline ACT Score & Project-based & Traditional \\
\hline Math & 24.9 & 26.6 \\
\hline Composite & 24.1 & 25.5 \\
\hline
\end{tabular}

There are many factors that could have caused the $6 \%$ differences in performance that were noted above, independent of which laboratory manual type was used. There was no attempt made to choose which students used the project-based laboratory manual. The students chose a section that would fit in their schedule and the laboratory manual type was assigned blindly before the semester began. Therefore, the academic ability of the students enrolled in each section was random and not necessarily equivalent. The table below shows that the traditional laboratory manual students scored on average 1.4 points higher than the project-based laboratory manual students on the ACT test. The table also indicates a 1.7-point higher average ACT Math component score for this group.

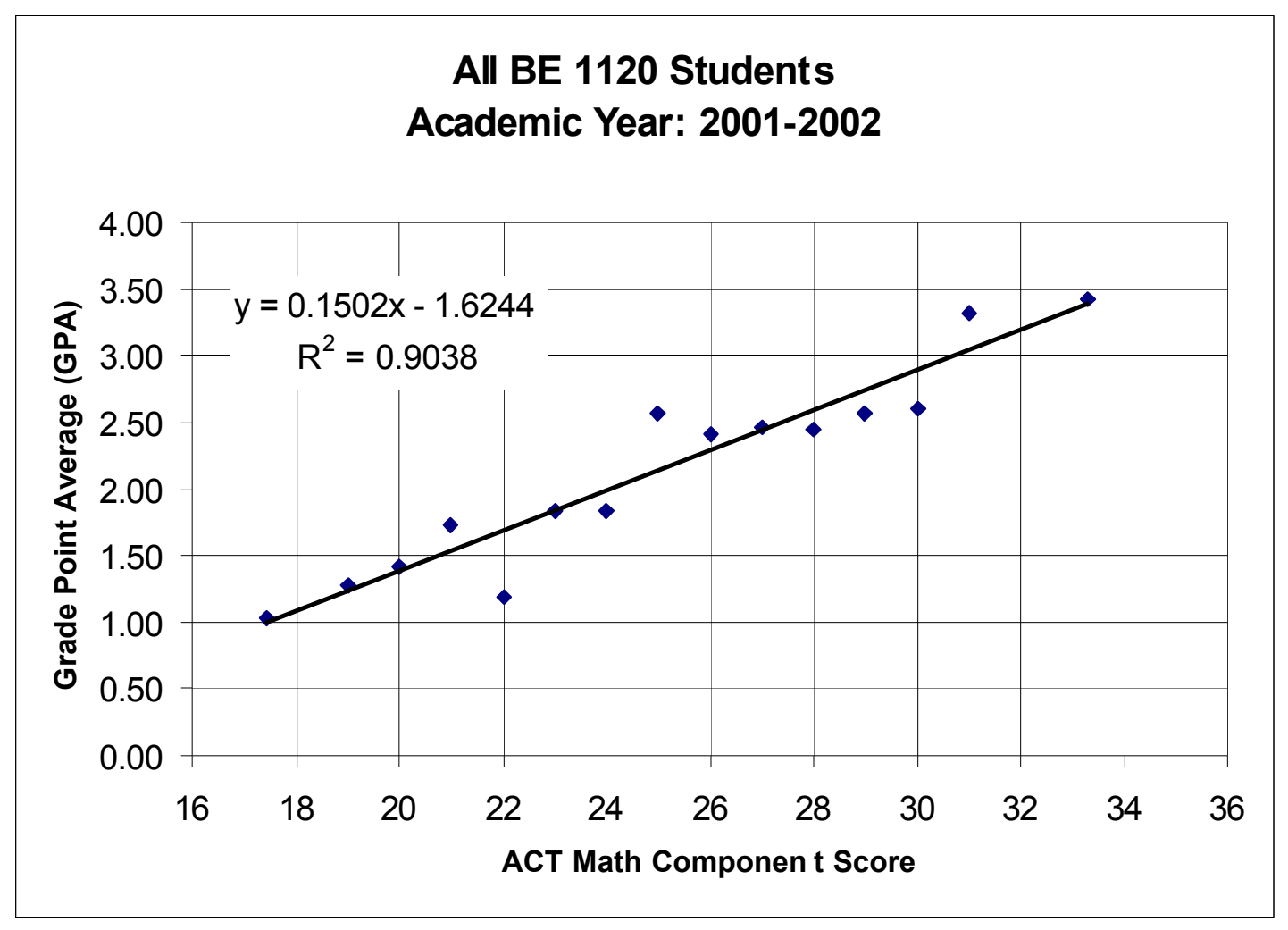

Figure 1: Linear Regression to Predict GPA based on ACT Math Component score. 
The difference in the Math component score is most notable when considering the material covered in the class. The course is a Basic Engineering class and not a Computer Science class and therefore all of the programming applications used are related to the engineering field. This field requires a considerable amount of math in the solution to its problems. In order to determine the effect a higher average Math ACT Component score would have on the success of the students in this class, the scores of all students enrolled in BE 1120 for the 2001-2002 academic year were evaluated. An average GPA was calculated for each ACT Math Component score level and these values were plotted. At either end of the scale a weighted average was used for the ACT Math Component score because of the small number of occurrences at these values. The resulting plot indicated a linear relationship and a linear regression was performed, as seen in Figure 1.

As is indicated on the plot, the agreement between the data and the trend line is very good. Using this relationship, the difference in GPA that can be expected when a difference in Math ACT Component score of 1.7 points exists is 0.25 points. The actual difference in GPA seen between the project-based laboratory manual group and the traditional laboratory manual group was 0.19 points. Therefore it is possible to attribute the lower GPA value to the fact that the students in the traditional laboratory manual group were more prepared for the course based on their mathematic ability.

\section{Summary}

Based on the evidence presented, there was no significant improvement in student performance when using a project-based laboratory manual over using a traditional laboratory manual comprised on randomly selected unrelated exercises. There is a belief that a more suitable project, that would not cause the level of confusion seen in the Xetron project, could produce results more consistent with those that were expected in this study. It is further believed that the learning style of the individual student could be a factor in the effectiveness of the laboratory manual type used. Unfortunately this data is not available and it is virtually impossible to control the placement of students, which would be required to make use of this learning style knowledge.

Due to the lack of significant impact on student learning, the project-based manual is not currently being used.

\footnotetext{
References:

${ }^{1}$ Joenathan, C., Bunch, R.M., \& Siahmakoun, A. "Project Oriented Laboratory Courses in Optics Education", SPIE, 2525, p 266-271, 1995.

${ }^{2}$ Craven, Kristine, Wayne, Scott, and Stiller, Al, “The Freshman Engineering Experience at West Virginia University," 1999 ASEE Annual Conference Proceedings, ASEE, 1999.

${ }^{3}$ Scott Wayne, Alfred Stiller, and Kristine Craven, "Integrating Design and Decision Making into Freshman Engineering at West Virginia University”, 1999 ASEE Annual Conference Proceedings, ASEE, 1999.

${ }^{4}$ Torrey, David A., “A Project Oriented Power Electronics Laboratory,” Proceedings of the 1993 IEEE $24^{\text {th }}$ Annual Power Electronics Specialist Conference”, IEEE, p 972-978, 1993.
} 
Dr. KRISTINE K. CRAVEN

Dr. Craven received a PhD in Mechanical Engineering from West Virginia University. She currently teachs programming to freshman engineering students as well as Thermodynamics, Dynamics, and Fluid Mechanics in the summer terms at Tennessee Technological University. Her research interests include recruitment and retention, numerical modeling in heat transfer and fluid flow, and other educational concerns. 